\title{
SOME TRAILS WITH VANILLIC DIETHYLAMIDE: A NEW ANALEPTIC $†$
}

\author{
A. Romagnoli, M.D. AND M. J. Diamond, M.B., CH.B.
}

"In somno securitas." Safety in sleep exists only when the awakening is controlled. A step was made in this direction in 1952 when vanillic diethylamide (3-methoxy-4-oxy-benzoic acid-diethylamide) was synthetized by Kvasnicka and $\mathrm{Kratzl}^{1}$ and tested by Ginzel ${ }^{2}$; its pharmacology and toxicity as a central nervous stimulant were then evaluated in the experimental animal. However, it was not until 1959 that this drug came back into focus. Vanillic diethylamide has a molecular weight of 223.6 and a melting point of $95.5^{\circ} \mathrm{C}$. It is a white crystalline powder, slightly soluable in water. The L.D. 50 is, in mice, $15 \mathrm{mg}$. $/ \mathrm{kg}$. intravenously and $90 \mathrm{mg} . / \mathrm{kg}$. orally. In rabbits, the respiratory volume increases 100 per cent after a dose of $2 \mathrm{mg}$. $/ \mathrm{kg}$. intravenously. The response is maximum in sixty seconds and terminates in ten minutes. It is fifteen times as effective as nikethamide and four times as effective as metrazol as a respiratory stimulant. ${ }^{3}$ This response occurs irrespective of the depressing cause, for example, barbiturates, morphine, alcohol, ether, and $\mathrm{CO}_{2}$ narcosis.,5,6,7 The onset is immediate and the duration brief. Orally, it lasts up to four hours. In humans, the blood pressure is unchanged or brought back to normal if previously depressed. ${ }^{8}$ There is no evidence of toxicity and no alteration of urine, blood or serum components have been found. ${ }^{3}$ However, there have been reports of sneezing, coughing, itching, flushing and even twitchings particularly during excessive doses. It must be concluded that this drug has a very low toxicity in comparison to its activity as a respiratory stimulant and arousing agent. ${ }^{9}$

We undertook some trials with vanillic diethylamide in view of these very encouraging reports. The patients were totally unselected (Table I). The age varied between 5 and 80 years; the duration of anaesthesia was from five minutes to two hours. We first decided to use it only after thiopentone administration and immediately found that the side effects were due to the rapid administration of a concentrated solution. We then made up a 1 per cent solution in normal saline and gave this very slowly. Our next finding was that. the dosage of vanillic diethylamide required to awaken the patient following thiopentone anaesthesia corresponded closely to the dosage of 2.5 per cent pentothal administered volume for volume. In other words, after a dose of $20 \mathrm{cc}$. of 2.5 per cent pentothal, $20 \mathrm{cc}$. of 1 per cent vanillic diethylamide were required to awaken the patient. This dose was administered intravenously over a period of three minutes. Although such a rule is empirical and lacking in quantitative values, it was nevertheless found by us to be safe, easily applicable and capable of giving the desired

\footnotetext{
-Trade name Emivan. Generously supplied by Arlington-Funk Laboratories.

†Presented at the Annual Meeting, Canadian Anaesthetists' Society, May 15-18, 1961.

$\$$ Department of Anaesthesia, Jewish General Hospital, Montreal, P.Q.
} 
TABLE I

Cases in IVhich Vanillic Diethylamioe was Used

\begin{tabular}{lr}
\hline \hline Laparotomies & 48 \\
Cystotomies & 17 \\
Orthopaedics & 18 \\
Hernias & 12 \\
Rectal & 7 \\
Tonsillectomies & 12 \\
D. and C. & 19 \\
Cystoscopies & 61 \\
Oesophagoscopies & 3 \\
Comas & 3 \\
& 200 \\
\hline
\end{tabular}

results even in the hands of the novice. It did not take many cases for us to realize how constant and reliable the effects of this new analeptic were. Then we extended its use to include every type of anaesthetic unconsciousness (Table II). The results continued to be consistently good. With appropriate dosage, the patients would wake during the administration and on occasions would relapse into a light sleep. They often began by rubbing their eyes, nose and mouth with

TABLE II

Types of ANaesthesia in Series

\begin{tabular}{lr}
\hline \hline Pent. Demerol $\mathrm{N}_{2} \mathrm{O}$ & 12 \\
Pent. ether $\mathrm{N}_{2} \mathrm{O}$ & 11 \\
Pent. $\mathrm{C}_{3} \mathrm{H}_{6}$ & 18 \\
Pent. $\mathrm{N}_{2} \mathrm{O}$ Fluothane & 65 \\
$\mathrm{~N}_{2} \mathrm{O}$ Fluoth. & 22 \\
Pent. $\mathrm{N}_{2} \mathrm{O}$ Trilene & 9 \\
Pentothal & 50 \\
Comas & 3 \\
Lytic cocktails & 10 \\
& 200 \\
\hline
\end{tabular}

well-coordinated movements, then consciousness returned progressively until they could answer questions even if their speech was slurred. The respiratory stimulation was always very good. There was no significant oscillation in blood pressure, but it was at this stage that, if the administration of even our diluted solution was too rapid, sneezing, coughing and laryngeal spasm would ensue. However, we can categorically state that we never once noticed muscle fasciculation or convulsive type movements. In our series (Table III), 153 patients had

TABLE III

SiDE EFFEcts

\begin{tabular}{lr}
\hline No side effects & 153 \\
Sneezing & 32 \\
Itching & 25 \\
Cough & 12 \\
Spasm & 2 \\
\hline
\end{tabular}


no side effects; 32 manifested sneezing; 25 complained of itchiness; 12 coughed, and only 2 exhibited laryngeal spasm. It must be pointed out that the total number of side effects is higher than the total number of cases treated simply because some patients manifested more than one side effect. Those who had spasm always coughed; those who sneezed often coughed; and those who showed itchiness, sometimes sneezed.

Included in our series were three cases of coma caused by the ingestion of depressants. Patient no: 1, A.V., a white female aged 62 years, weighing $120 \mathrm{lb}$. had taken an undetermined amount of 2-methyl-2-n-propyl-1, 3-propanediol dicarbamate and 2-diethylaminoethyl benzilate $\mathrm{HCl}\left({ }_{(}\right.$Deprol $\left.{ }^{\circledR}\right)$, codeine, pentobarbital and 7-chloro-2-methylamino-5-phenyl-3H-1, 4-benzodiazepine 4-oxide $\mathrm{HCl}\left(\right.$ Librium $\left.^{\circledR}\right)$. She was admitted around midnight; cyanotic, Cheyne-Stokes respirations, blood pressure $120 / 80$, pulse 120 . She was treated conservatively until ten o'clock the following morning when there was no improvement. The blood pressure was $154 / 92$, respirations 24 , pulse 100 and temperature $100.2^{\circ} \mathrm{F}$. One hour later the blood pressure was 190/90, respirations 30, and pulse 126 . Over a period of fifteen minutes, $600 \mathrm{mg}$. of vanillic diethylamide 1 per cent solution was administered intravenously. The patient showed coordinated movement, coughing, corneal reflex and her blood pressure was 185/90, pulse 120 and respirations 24 (deep). Four hours later the blood pressure was 140/80, respirations 24 , pulse 100 and temperature $99.4^{\circ} \mathrm{F}$. Then $400 \mathrm{mg}$. of the same solution was administered over a fifteen-minute period. Breathing was deep, the patient moved and all reflexes were present. A pharyngeal airway was not tolerated. At 7 P.M., after another interval of four hours, the blood pressure was $140 / 90$, pulse 100 , respirations 28 and temperature $98.6^{\circ} \mathrm{F}$. Again $400 \mathrm{mg}$. were administered in the same way. The response was once more exellent and the patient was almost awake. She rubbed her eyes, cleared her throat and turned over. The same dose was repeated four hours later. The patient was awake at 9 A.M. the following morning, fully conscious, hostile and resentful.

Patient no. 2, R. M., a white female, 27 years of age,- weighing $132 \mathrm{lb}$, had taken 9 grains of pentobarbital and $300 \mathrm{mg}$. of 7-chloro-2-methylamino-5-phenyl3H-1, 4-benzodiazepine 4-oxide $\mathrm{HCl}$ (Librium ${ }^{\circledR}$ ). She was admitted at 10 P.M. and various analeptics were given during the night. At 9 A.M. deep reflexes were present but there was no corneal reflex. Respirations were 30 and shallow. The blood pressure was 100/60 and the left lung was poorly aerated. A dose of $400 \mathrm{mg}$. of vanillic diethylamide was administered. Slight movement of the limbs was obtained and there was an effort to cough. At 11 A.M. the same dose was given. The blood pressure was unchanged but the response was good with coughing, movement and return of the corneal reflex At 1 P.M. the blood pressure was $100 / 60$ and an additional $400 \mathrm{mg}$. of vanillic diethylamide were given. This resulted in cough, movements, corneal reflex and good lung expansion. At 3 P.M. the dose of $400 \mathrm{mg}$. was repeated. At this time the conjunctival reflex returned. At 5 P.M. the eyelid reflex returned after another dose' of the same amount of vanillic diethylamide. At 7 P.M. another $400 \mathrm{mg}$. were administered and the patient awoke and spoke and then fell into a light sleep until next morning, when she was well. Her blood pressure was 125/84 and pulse 78 . 
Patient no. 3, N.N., was a 19-year-old white male, weighing $200 \mathrm{lb}$. He was admitted at 10 A.M. in coma since the previous evening because of ingestion of a large and undetermined amount of tranylcypromine-trifluoperazine (Par. stalin $\left.{ }^{(}\right)$, 7-chloro-2-methylamino-5-phenyl-3H-1, 4-benzodiazepine 4-oxide $\mathrm{HCl}$ (Librium ${ }^{\mathbb{B}}$ ), and pentobarbital. His respiration was inadequate, blood pressure $100 / 60$, pulse 110. He had no reflexes at all, no response to deep pain, and some falling back of the tongue. In view of the condition, an airway was inserted and vanillic diethylamide was administered in large quantities (10 gm.) by drip during the succeeding three hours. This caused good respiratory efforts with adequate exchange, accompanied by cough and clearing of the upper respiratory tract. In the afternoon, the patient had gone back into a state of complete absence of reflexes and inadequate respiratory exchange. The administration of $500 \mathrm{mg}$. of vanillic diethylamide in four minutes caused good respiratory stimulus and cough which brought up a large quantity of green exudate. The temperature had risen to $103^{\circ} \mathrm{F}$. rectally. Bronchial toilet was done immediately under direct vision. A no. 10 endotracheal tube was inserted and connected to the Bird's respirator. General medical therapy was also instituted. A vanillic diethylamide drip (10 mg./cc.) was run at 30 drops per minute. Single injections of vanillic diethylamide were done at four-hour intervals. The dose administered was always that required to cause cough for clearing of the upper respiratory passages. This dose was, at the beginning, approximately $1000 \mathrm{mg}$. in five minutes. It decreased to $400 \mathrm{mg}$. or less at the end of the third day when the patient regained consciousness. The coma lasted 71 hours. A tracheostomy was performed 24 hours after admission.

The first and the second patients presented received $1.8 \mathrm{gm}$. and $2.4 \mathrm{gm}$. respectively, which we consider a small dose but adequate to gain the desired result. On the other hand, in view of the greater depth of coma, the third patient received a total dose of $23.2 \mathrm{gm}$. to obtain the same result.

Vanillic diethylamide was administered to a large number of patients under the most varied conditions, and even in large doses we always obtained the desired results with a minimum of side effects. This drug is indeed an analeptic without any antidotic activity towards any of the depressants used for or in relation to anaesthesia. However, it has an arousing effect against any anaesthetic agent, be it pentothal or ether tranquillizers or opiates-a great quality indeed. The dose necessary to achieve the required effect will, however, vary. This dose is easily gauged because vanillic diethylamide has a rapid onset and a short duration of action (10 minutes average). The mode of action is widely discussed and variously attributed to the carotid chemo-receptors or directly on the medullary centres. ${ }^{10}$ Our clinical impression is that vanillic diethylamide has indeed an action on all the central nervous system with generalized stimulation of the motor, sensory and medullary centres with specific activity on the respiration. Compared with a single dose of pentothal, a single dose of vanillic diethylamide is quite adequate to achieve and maintain consciousness, but against longer-acting agents, such as ether or the phenothiazine derivatives, vanillic diethylamide on account of its evanescence, must be administered by drip or the patient will quickly revert to as deep a sleep as before. In the case of comas, we feel that all that can be hoped of vanillic diethylamide is a. stirring 
up action with deep breathing and coughing and swallowing at regular intervals of two to four hours so as to give the organism the time to rid itself of the intoxicating drug. Vanillic diethylamide is no substitute for all the measures normally necessary in the treatment of acute barbituric poisoning such as maintenance of adequate ventilation, postural drainage, antibiotics, etc. The side effects elicited are minimal and of no consequence even in extremely large doses and it must be clear that they are always regulated by a ratio derived from the condition of the patient (depth), quantity of the drug, and speed of administration. As side effects, we encountered itching, sneezing, coughing and laryngeal spasm mostly during the early stages of our experience. The blood pressure was unaffected or was brought up to normal if previously depressed. The cardiac rhythim in our experience was never altered.

Vanillic diethylamide is no miracle drug, but it is indeed an extremely safe and valuable substance in counteracting pharmacological unconsciousness.

\section{SUMMARY}

Vanillic diethylamide, an analeptic of recent discovery, was tested on 200 patients who had received varied anaesthetics, including three barbiturate and tranquillizer intoxications. The clinical findings and the results of this promising drug are discussed.

\section{RÉSUMÉ}

Nous avons étudié les effects d'un analeptique découvert récemment: le diéthylamide vanillique; nous avons fait cette étude sur 200 malades qui avaient reçu différents agents anesthésiques, dont trois cas d'intoxication aux barbituriques et aux tranquilisants. Nous faisons part des observations cliniques et des résultats obtenus à la suite de l'administration de cette drogue prometteuse.

\section{REFERENCES}

1. Krasnicka \& Kratzl. On the Chemistry of Vanillin and its Derivatives; On Alkylamides, Various Aromatic Acids, in particular Vanillic Acid. Monatsh. f. Chemie. 83: 18 (1952).

2. Ginzet, K. H. A New Vanillin Derivative with Strong Analeptic Activity. Wien. Ztschr. in. Med. 33: 16 (1952).

3. U.S. Vitamin \& Pharmaceutical Corp: Research Division. Personal communication.

4. Auinger, W.; Kaindi, F.; Salzmann, F.; \& Weissel, W. The Respiratory and Circulatory Effects of 3-methoxy-4-oxybenzoic and diethylamide, Wien, Ztschr. inn. Med. 33: 23 (1952).

5. Martischnig. R. The Clinical Effect of a New Restorative in Children. Wien. klin. Wchnschr. 102: 773 (1952).

6. Schoner, W. Clinical Testing of Vandid in Infants and Pretnature Babies. Wien. med. Wchnschr. 102: 773 (1952).

7. Mortz, E. The Treatment of Severe Intoxication with Vanillic Diethylamide. Wien. med. Wchenschr. 103: 699 (1953).

8. Bernstine, M. L. \& Moskal, J. P. Effect of Vanillic Diethylamide on Arousal and Awakening Time following Thiopental Anesthesia. Anesthesiology, 21: 90 (1960).

9. Mirler, W. F., Archer, R. K., \& Taylor, H. F. An Evaluation of the Respiratory Analeptic, Vanillic Diethylamide, in Various Forms of Severe Respiratory Failure. A.M.A. Meeting, Miami Beach (June, 1960).

10. SAD, S. I. Experience with a New Respiratory Center Stimulant. Federation Proc. 19: 373 (1960). 